\title{
ĐĂC ĐIỂM LÂM SÀNG VÀ CÂN LÂM SÀNG, HÌNH ẢNH SIÊU ÂM DOPPLER XUYÊN SO (TCD) CỦA BỆnH NHÂN CHẢY MÁU NÃO DO VÕ̃ DỊ DẠNG THÔNG ĐộNG TĨNH MẠCH NÃO (AVM)
}

\section{TÓM TẮT.}

Mục tiêu: Mô tả đặc điểm lâm sàng, cận lâm sàng, hình ảnh siêu âm Doppler xuyên sọ từ đó xác định giá trị giá trị của siêu âm Doppler xuyên sọ ở bệnh nhân chảy máu não do võ̃ dị dạng thông động tĩnh mach não. Đối tượng nghiên cứu: Tất cả các bệnh nhân được chẩn đoán là dị dạng thông động-tĩnh mạch não có biến chứng chảy máu có làm siêu âm Doppler xuyên sọ được điêu trị tại Bệnh viện Bạch Mai từ 10/2019 đến 07/2021. Phương pháp nghiên cứu: Mô tả cắt ngang. Kết quả: Tuổi trung bình của nhóm bệnh nhân AVM võ là $43 \pm 14,7$ tuổi, tỷ lệ nam $/$ nư $=1,27 / 1$. Bệnh nhân vào viện vì buốn nôn, nôn chiếm tỷ lệ $97,2 \%$, tiếp theo là triệu chứng đau đâuu chiếm $94,4 \%$, có $50 \%$ bệnh nhân vào vì liệt nửa người. Vị trí chảy máu hay gặp là chảy máu thùy. Các ổ dị dạng có kích thước nhỏ và trung bình là hay võ̃ nhất chiếm $97,2 \%$. Nguồn cấp máu cho ổ dị dạng võ cửa động mạch não giữa là nhiều nhất chiếm $52,78 \%$. Ổ dị dạng được nuôi bằng 1 đến 3 cuống nuôi (chiếm $91,67 \%$ ) và có một tĩnh mạch dẫn lưu duy nhất (chiếm 72,2\%) là những ổ dễ vỡ. Tỷ lệ phát hiện được dị dạng động mạch não giữa trên siêu âm Doppler xuyên sọ là cao nhất chiếm $89,47 \%$. Siêu âm Doppler xuyên sọ có tỷ lệ phát hiện ổ dị dạng có kích thước trung bình và lớn lần lượt là $93,75 \%$ và $100 \%$, trong khi đó với ổ dị dạng có kích thước nhỏ thì tỷ lệ phát hiện có 40,9\%. Tốc độ dòng chảy bên nuôi ổ dị dạng của động mạch não giữa có tốc độ tăng hơn bền đối diện có ý nghĩa với $p<0,05$. Kết luận: Độ tuổi hay gắp nhất của các bệnh nhân AVM vỡ là từ trên 40 tuối chiếm tỷ lệ $63,9 \%$; tuổi trung bình $43 \pm 14,7$. Bệnh gặp ở cả hai giới với tỷ lể nam/nữ là $1,27 / 1$. Chảy máu do vỡ AVM là chảy máu thùy chiếm $85.72 \%$. Ô dị dạng vỡ thường là ổ có kích thước nhỏ $<3 \mathrm{~cm}$, có một tĩnh mạch dẫn lưu duy nhất. TCD là phương pháp hữu ích để chẩn đoán các dị dạng thông động tĩnh mạch não nó có độ nhạy cao với các AVM có kích thước trung bình.

Tư khóa: Dị dạng thông động tĩnh mạch não võ, siêu âm Doppler xuyên sọ.

\section{SUMMARY}

SUBCLINICAL AND CLINICAL CHARACTERISTICS, TRANSCRANIAL DOPPLER (TCD) ULTRASOUND IMAGING

\footnotetext{
*Bệnh Viện Đa khoa tỉnh Thanh Hóa

**Bệnh viện Bạch Mai

Chịu trách nhiệm chính: Lê Hồng Ninh

Email: bsleninh85@gmail.com

Ngày nhận bài: 3.6.2021

Ngày phản biện khoa học: 28.7.2021

Ngày duyệt bài: 5.8.2021
}

\author{
Lê Hồng Ninh*, Võ Hồng Khôi**
}

IN PATIENTS WITH RUPTURED CEREBRAL ARTERIOVENOUS MALFORMATION (AVM)

Objectives: To describe subclinical and clinical characteristics, transcranial Doppler (TCD) ultrasound imaging; and assess the value of transcranial Doppler ultrasoundin patients with intracranial hemorrhage due to ruptured cerebral arteriovenous malformation (AVM). Methods: A descriptive cross-sectional study of 36 cases with ruptured cerebral arteriovenous malformation (AVM) who weretreated at Bach Mai Hospital from October 2019 to July 2021. Results: Mean age was $43 \pm 14,7$ years old, male/female ratio was 1,27/1. Admisssion reasons: Nausea/vomitting were $97,2 \%$, headache was $94,4 \%$, altered level of consciousness was $30.6 \%$ and $50 \%$ with hemiplegia. The common hemorrhagic location were in cerebral lobules. The percentage of hematoma sizes smaller than $3 \mathrm{~cm}$, from 3 to $6 \mathrm{~cm}$ and greater than $6 \mathrm{~cm}$ were $58.3 \%, 38.9 \%$, and $2.8 \%$ respectively. The ruptured AVM feeding vessels originate from midle cerebral artery were $52,78 \%$. The AVM had 3 or 4 feeding arteries were $91,67 \%$, had more than 4 feeding arteries were $8,33 \%$. The AVM with pure one draining vein was $72,2 \%$, with 2 or more draining veins was $27.8 \%$. The confirmed diagnostic rate of AVM feb by middle cerebral artery branches by TCD ultrasound was $89,47 \%$. Postive prediction value based on CTA for small, medium and large AVM was 40,9\% 93,75\% and $100 \%$ respectively. Mean flow velocity on the feeding vessels originate from MCA was higher than those in the contralateral MCA. (significant difference, with $\mathrm{p}<0,05)$. Conclusion: The predominant age group in ruptured AVM was 40 years old and above $(63,9 \%)$; the mean age was $43 \pm 14,7$, male/female ratio was $1,27 / 1$. The common hemorrhagic location were in cerebral lobules $(85,72 \%)$, hematoma sizes smaller than $3 \mathrm{~cm}$ with pure one draining vein was $72,2 \%$. TCD ultrasound was the useful tool to diagnose the medium and large AVM with high sensitivity.

Key words: Ruptured cerebral arteriovenous malformation (AVM). transcranial Doppler (TCD)

\section{I. ĐẶT VẤN ĐỀ}

Dị dạng động tĩnh mạch não (AVM) là bất thường bẩm sinh mạch máu trong não, xuất hiện do quá trình phát triển bất thường của hệ thống mạch máu, tạo ra sự thông thương trực tiếp giữa các động mạch não với tĩnh mạch não [1]. Dị dạng thông động-tĩnh mạch não gồm có ba thành phần là các động mạch nuôi, ổ dị dạng và tĩnh mạch dẫn lưu [2].

Khoảng 45\% trường hợp bAVM bị võ [3] và tỷ lệ tử vong do võ các bAVM chiếm $10 \%$. Có đến 88\% bệnh nhân dị dạng thông động-tĩnh mạch 
não thường không biểu hiện các triệu chứng lâm sàng rõ trong giai đoạn đâuu của cuộc đời [3], bAVM chiếm 25\% đột quy. xuất huyết ở người lớn dưới 50 tuổi.

Siêu âm Doppler xuyên sọ là kỹ thuật chẩn đoán hình ảnh có nhiều giá trị trong việc thăm dò các mạch máu nội sọ. Một trong những tác dụng quan trọng nhất là gợi ý chẩn đoán dị dạng thông động-tĩnh mạch não và theo dõi kết quả điều trị. Vì vậy,chúng tôi tiến hành nghiên cứu đề tài: "Đặc điểm lâm sàng và cận lâm sàng, hinh ảnh siêu âm Doppler xuyên sọ của bệnh nhân chảy máu não do vỡ dị dạng thông động tĩnh mạch não"với hai mục tiêu:

1. Mô tả đặc điểm lầm sàng, cận lâm sàng, hinh ảnh siêu âm Doppler xuyên sọ ở bệnh nhân chảy máu não do vỡ dị dạng thông động tĩnh mạch não.

2. Xác định giá trị của siêu âm Doppler xuyên sọ trong chân đoán ở bệnh nhân chảy máu não do vỡ dị dạng thông động tĩnh mạch não.

\section{II. ĐỐI TƯợNG VÀ PHƯƠNG PHÁP NGHIÊN CỨU}

2.1 Đối tượng: Tất cả các bệnh nhân được chẩn đoán là dị dạng thông động-tĩnh mạch nã̃o có biến chứng chảy máu có làm siêu âm Doppler xuyên sọ đáp ứng đủ các tiêu chuẩn lựa chọn được điều trị tại Bệnh viện Bạch Mai từ 10/2019 đến 07/2021.

2.2 Phương pháp nghiên cứu: Phương pháp mô tả cắt ngang 36 ca bệnh. Bệnh nhân nhập viện được khám lâm sàng, làm các xét nghiệm cận lâm sàng, siêu âm Doppler xuyên sọ. Ghi nhận thông tin nghiên cứu theo mẫu bệnh án có sự đồng thuận của bệnh nhân và/hoặc gia đình.

2.3. Xử lý số liệu: Theo phương pháp thông kê y học, sử dụng phần mềm SPSS 25.0

\section{KẾT QUẢ NGHIÊN CứU}

3.1. Các đặc điểm cơ bản của bệnh nhân nhân

Bảng 3.1. Các đặc điểm cơ bản của bệnh

\begin{tabular}{|c|c|c|}
\hline Đặc điểm & $\begin{array}{c}\text { Số bệnh } \\
\text { nhẩn }\end{array}$ & $\begin{array}{c}\text { Tỷ lệ } \\
\mathbf{( \% )}\end{array}$ \\
\hline Nam & 20 & 55,6 \\
\hline Nữ & 16 & 44,4 \\
\hline Tuối trung bình & $43 \pm 14,7$ tuối \\
\hline \multicolumn{2}{|c|}{ Lý do vào viện } \\
\hline Rối loạn ý thức & 11 & 30,6 \\
\hline Chóng mă̆t & 3 & 8,3 \\
\hline Nhức đâuu & 34 & 94,4 \\
\hline Buồn nôn, nôn & 35 & 97,2 \\
\hline
\end{tabular}

\begin{tabular}{|c|c|c|}
\hline Cơn động kinh & 5 & 13,9 \\
\hline Tê và/hoăc liệt nửa người & 18 & 50 \\
\hline
\end{tabular}

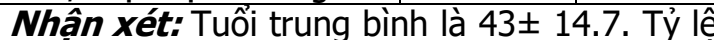
nam/nữ $=1,27 / 1$. Buôn nôn, nôn và đau đâuu là những triệu chứng chính khiến bệnh nhân nhập viện với tỷ lệ lần lượt là $97,2 \%$ và $94,4 \%$.

\subsection{Vị trí bAVM vơ}

Bảng 3.2. Vị trí bAVM võ

\begin{tabular}{|c|c|c|}
\hline \multicolumn{2}{|c|}{ Vị trí bAVM vỡ } & Tỷ lệ (\%) \\
\hline Thùy trán & 10 & 23,81 \\
\hline Thùy thái dương & 10 & 23,81 \\
\hline Thùy đỉnh & 7 & 16,67 \\
\hline Thùy chấm & 9 & 21,43 \\
\hline Đồi thị, nhân xám, thế chai & 2 & 4,76 \\
\hline Tiếu não & 4 & 9,52 \\
\hline
\end{tabular}

Nhận xét: Vị trí chảy máu hay gặp nhất là chảy máu thùy chiếm $85,72 \%$, chảy máu vùng sâu trong não chiếm tỷ lệ thấp.

3.3. Kích thước ổ bAVM võ

Bảng 3.3. Kích thước ổ bAVM vỡ

\begin{tabular}{|c|c|c|}
\hline Kích thước & Số bệnh nhân & Tỷ lệ \% \\
\hline$<3 \mathrm{~cm}$ & 21 & 58,33 \\
\hline $3-6 \mathrm{~cm}$ & 14 & 38,89 \\
\hline$>6 \mathrm{~cm}$ & 1 & 2,78 \\
\hline
\end{tabular}

Nhân xét: Số lượng các ổ bAVM võ có kích thước < 3cm chiếm tỷ lệ lớn nhất với 58,33\%

3.4. Đặc điểm mạch máu của ổ dị dạng.

Bảng 3.4. Đặc điểm mạch máu của ổ di dạng

\begin{tabular}{|c|c|c|}
\hline Nguồn cấp máu & & Tỷ lệ \% \\
\hline ĐM não giữa & 19 & 52,78 \\
\hline ĐM não trước & 9 & 25 \\
\hline ĐM não sau & 12 & 33,33 \\
\hline ĐM tiếu não sau dưới & 1 & 2,78 \\
\hline ĐM tiếu não trước dưới & 1 & 2,78 \\
\hline ĐM tiếu não trên & 2 & 5,56 \\
\hline \multicolumn{3}{|c|}{ Số lượng cuống nuôi } \\
\hline 1 động mạch nuôi duy nhất & 13 & 36.11 \\
\hline 2 động mạch nuôi & 14 & 38.8 \\
\hline 3 động mạch nuôi & 6 & 16.66 \\
\hline$\geq 4$ động mạch nuôi & 3 & 8.33 \\
\hline \multicolumn{3}{|c|}{ Số lượng tĩnh mạch dân lưu } \\
\hline 1 tĩnh mạch dần lưu & 26 & 72.2 \\
\hline$\geq 2$ tĩnh mạch dân lưu & 10 & 27.8 \\
\hline
\end{tabular}

Nhận xét: Nguồn cấp máu cho AVM từ động mạch não giữa là nhiều nhất chiếm $52,78 \%$. AVMM được nuôi bằng 1 cuống nuôi chiếm tỷ lệ nhiêuu nhất với $36,11 \%$. Trong khi đó, AVM có 1 tĩnh mạch dẫn lưu cũng chiếm đa số với 72,2\%.

3.5. Tỷ lệ thăm dò được các động mạch trên TCD so với kết quả chụp mạch đối chiếu với kích thước ổ dị dạng.

Bảng 3.5. Tỷ lệ thăm dò được các động mạch trên TCD so với kêt quả chụp mạch đôi chiếu với kích thước ổ dị dạng 


\begin{tabular}{|c|c|c|c|c|}
\hline \multicolumn{2}{|c|}{ Kích thước ổ dị dạng } & $\begin{array}{l}\text { Số trường hợp nuôi ổ dị dạng } \\
\text { (Xác định dựa vào chụp mạch) }\end{array}$ & $\begin{array}{l}\text { Số trường hợp thăm } \\
\text { dò được qua siêu âm }\end{array}$ & $\begin{array}{l}\text { Tỷ lệ } \\
\text { \% }\end{array}$ \\
\hline \multirow{3}{*}{ Nhỏ } & ĐM não giữa & 7 & 5 & \multirow{3}{*}{40.9} \\
\hline & ĐM não trước & 5 & 2 & \\
\hline & ĐM não sau & 10 & 2 & \\
\hline \multirow{3}{*}{$\begin{array}{c}\text { Trung } \\
\text { bình }\end{array}$} & ĐM não giữa & 11 & 11 & \multirow{3}{*}{93.75} \\
\hline & ĐM não trước & 3 & 2 & \\
\hline & ĐM não sau & 2 & 2 & \\
\hline \multirow{3}{*}{ Lớn } & ĐM não giữa & 1 & 1 & \multirow{3}{*}{100} \\
\hline & ĐM não trước & 1 & 1 & \\
\hline & ĐM não sau & 0 & 0 & \\
\hline
\end{tabular}

Nhận xét: Siêu âm Doppler xuyên so có tỷ lệ phát hiên ố di dang có kích thước trung bình và lớn lần lượt là $93,75 \%$ và $100 \%$, tỷ lệ thấp hơn với các ổ dị dạng có kích thước nhỏ với chỉ 40,9\%.

\subsection{Sự thay đổi tốc độ dòng máu và chỉ số mạch}

Bảng 3.6. Sự thay đối tốc độ dòng máu và chỉ số mạch

\begin{tabular}{|c|c|c|c|c|}
\hline & \multicolumn{2}{|c|}{ Tốc độ dòng chảy trung bình } & \multicolumn{2}{c|}{ Chỉ số mạch } \\
\hline & $\begin{array}{c}\text { Bên nuôi ổ dị dạng } \\
\text { Bên đối diện }\end{array}$ & $\begin{array}{c}\text { Bên nuôi ổ dị dạng } \\
\text { ĐM nãn đối diện }\end{array}$ \\
\hline ĐM nước & $\begin{array}{c}68,35 \pm 22,82 \\
(n=5)\end{array}$ & $\begin{array}{c}62,76 \pm 28,34 \\
(n=4)\end{array}$ & $\begin{array}{c}0,69 \pm 0,28 \\
(n=5)\end{array}$ & $\begin{array}{c}0,82 \pm 0,24 \\
(n=4)\end{array}$ \\
\hline ĐM nã̃o sau & $\begin{array}{c}93,29 \pm 31,93 \\
(n=17)\end{array}$ & $\begin{array}{c}77,52 \pm 18,36 \\
(n=15)\end{array}$ & $\begin{array}{c}0,64 \pm 0,19 \\
(n=17)\end{array}$ & $\begin{array}{c}0,85 \pm 0.34 \\
(n=15)\end{array}$ \\
\hline $\begin{array}{c}46,12 \pm 25,67 \\
(n=4)\end{array}$ & $\begin{array}{c}42,56 \pm 7,08 \\
(n=2)\end{array}$ & $\begin{array}{c}0,58 \pm 0,35 \\
(n=4)\end{array}$ & $\begin{array}{c}0,76 \pm 0,24 \\
(n=2)\end{array}$ \\
\hline
\end{tabular}

Nhận xét: Tốc độ dòng chảy bên nuôi ố dị dạng của động mạch não giữa lớn hơn hơn bên đối diện có ý nghĩa thống kê với $p<0,05$.

\section{BÀN LUÂN}

Tuổi trung bình của nhóm nghiên cứu là $43 \pm$ 14,7 dao động từ 28,3 đến 57,7 tuổi (tuổi không cân phải là biến thập phân). Nhóm tuổi thường gặp nhất là trên 40 , chiếm tỷ lệ $63,9 \%$. Theo Phan Văn Đức [4] tuổi trung bình khi phát hiện bệnh nhân AVM là $34,87 \pm 14,38$. Theo Marco [5] tuổi trung bình là 31. Như vậy, độ tuổi phát hiện $\mathrm{AVM}$ võ̃ trong nghiên cứu của chúng tôi là cao hơn so với các nghiên cứu trong nước và quốc tế điều này có thể lý giải do kích thước cõ mẫu chưa đủ lớn.

Lý do vào viên chiếm tỷ lệ cao nhất là nôn hoặc/và buồn nồn $(97.2 \%)$, nhức đầu với tính chất dữ dội chiếm 94,4\% các triệu chứng trên là hậu quả của chảy máu gây ra tắng áp lực trong so hoăc kích thích trực tiếp vào trung tâm nôn ở sàn não thất IV. Trongnghiên cứu của chúng tôi, có 11 trường hợp bệnh nhân rối loạn ý thức (chiếm 30,6\%). Trong đó, duy nhất một trường hợp có điểm Glasgow là 8, số còn lại dao động từ từ 10 đến 14 điểm. Như vậy bệnh nhân AVM não võ vào viện vì rối loạn ý thức thường không biểu hiện râm rộ, điều này có thể lý giải do bệnh học của chảy máu não căn nguyên AVM là do võ tĩnh mạch (Deruty [6]). Tê và liệt nửa người cũng là các triệu chứng thường gặp với tỷ lệ $50 \%$ và $52,9 \%$.

Vị trí chảy máu hay gặp nhất là chảy máu thùy chiếm $85,72 \%$, chảy máu vùng sâu trong não chiếm tỷ lệ thấp. Kết quả này tương tự với nghiên cứu của Phan Văn Đức [4], Phạm Hồng Đức [7] và Marco [4].

Trong nghiên cứu của chúng tôi, số AVM võ có kích thước nhỏ và trung bình chiếm 97,22\%, tương tự nghiên cứu của Phạm Hồng Đức [7] và Marco [4]. Như vâyy kích thước ổ di dang vỡ theo nhiều nghiên cứu có liên quan đến hiện tượng chảy máu não. Ổ dị dạng có kích thước nhỏ và trung bình có nguy cơ võ cao hơn ổ có kích thước lớn.

Đônng mạch não giữa tham gia cấp máu cho ổ dị dạng chiếm 52,78\% các trường hợp, động mạch não trước là $20,45 \%$, động mạch não sau là $27,27 \%$. Ngoài ra một số ố dị dạng còn được cấp máu bởi các nhánh động mạch tiểu não. Kết quả này phù hợp với nhận định của Phạm Hồng Đức [7] cho rằng khu vực động mạch não giữa là khu vực hay gặp nhất bởi vì động mạch não giữa là một động mạch lớn và là nguồn cung cấp máu cho phần lớn bán cầu não của hệ tuần hoàn trước.

Trong nghiên cứu của chúng tôi phần lớn các ổ dị dạng võ có từ hai cuống mạch nuôi trở lên $(63,89 \%)$, các ổ dị dạng vỡ thường là những ổ có một tînh mạch dẫn lưu duy nhất $(72,2 \%)$ điêu này cũng tương tự với các nghiên cứu của nhiêu tác giả khác.

Siêu âm Doppler xuyên sọ phát hiện ổ dị dạng có kích thước trung bình và lớn lần lượt là 
$93,75 \%$ và $100 \%$, trong khi đó với ổ dị dạng có kích thước nhỏ thì tỷ lệ phát hiện thấp hơn với 40,9\%. So sánh tốc độ dòng chảy bên nuôi ổ dị dạng với bên đối diện, chỉ có động mạch não giữa có tốc độ tăng lớn hơn có ý nghĩa thống kê với $p<0,05$. Theo nghiên cứu của Phan Văn Đức [4] về độ nhạy và độ đặc hiệu tính theo kích thước ổ dị dạng thì nhóm có kích thước trung bình và lớn có độ nhạy cao (thấp nhất là $87,5 \%$ cao nhất là 100\%). Mặt khác, với nhóm kích thước nhỏ thì xấp xỉ 50\% là không phát hiện được trên siêu âm xuyên sọ. Kết quả này của chúng tôi cũng gần tương tự với kết quả của Mast và cộng sự [8] khi nghiên cứu 114 bệnh nhân AVM với siêu âm Doppler xuyên sọ có độ nhạy của tốc độ trung bình và chỉ số mạch lần lượt là $85 \%$ và $63 \%$ còn khi phân nhóm thì nhóm kích thước trung bình và lớn cũng có độ nhay khá cao (từ 73 đến 100\%) còn nhóm kích thước nhỏ thì có độ nhạy khá thấp 39\% và $31 \%$ lần lượt theo tốc độ trung bình và chỉ số mạch. Về độ đặc hiệu có giá trị là $96 \%$ và $100 \%$ lần lượt theo tốc độ dòng chảy và chỉ số mạch.

\section{KẾT LUẬN}

Độ tuổi hay gặp nhất của các bệnh nhân AVM võ là từ trên 40 tuổi chiếm tỷ lệ $63,9 \%$; tuổi trung bình $43 \pm 14,7$. Bệnh gặp ở cả hai giới với tỷ lệ nam/nữ là 1,27/1. Chảy máu do võ AVM là chảy máu thùy chiếm $85,72 \%$. Ổ dị dạng võ thường là ổ có kích thước nhỏ $<3 \mathrm{~cm}$, có một tĩnh mạch dẫn lưu duy nhất. TCD là phương pháp hữu ích để chẩn đoán các dị dạng thông động tĩnh mạch não nó có độ nhạy cao với các AVM có kích thước trung bình.

\section{TÀI LIÊU THAM KHẢO}

1. Friedlander RM. Arteriovenous malfor- mations of the brain. N Engl J Med 2007; 356:2704-12.

2. Cognard C, Spelle L., and Pierot L. (2004), Pial arteriovenous malformations in: Intracranial vascular malformations and aneurysm, Springer. 39-92.

3. Shaligram S.S., Winkler E., Cooke $D$. và cộng sự. (2019). Risk factors for hemorrhage of brain arteriovenous malformation. CNS Neurosci Ther, 25(10), 1085-1095.

4. Phan 'Văn Đức, Lê Văn Thính, Hoàng Văn Thuận (2018), siêu âm Doppler xuyên so và hình ảnh chụp mạch máu não của dị dạng thông động-tĩnh mạch nã̃o.

5. Marco A.Stefani, Phillip J.Porter, et al (2002), Large and deep brain arteriovenous malformation are associated with risk of future hemorrhage, Stroke, 3. 1220.

6. Deruty $R$, et al (1985), Les malformations Arterio-veineuses Cerebrales, Neurochir, 31. 21-29

7. Pham Hông Đức, Pham Minh Thông, Lê Văn Thính (2010), Các yễu tố cấu trúc mạch liên quan đên biểu hiện xuất huyết của dị dạng động tînh mach não, Tạp chí $Y$ học thực hành (705) số 2, 52-55.

8. Mast H, Mohr JP, Osipov A, et al (1995) Steal is an unestablished mechanism for the clinical presentation of cerebral arteriovenous malformations, Stroke, 26. 1215-1220

\section{GIÁ TRI CỦA XUNG KHUẾCH TÁN TRONG UNG THƯ TUYẾN TIỀN LIÊTT: VÙNG NGOẠI VI VÀ VÙNG CHUYỂN TIẾP}

\section{TÓM TẮT}

Mục tiêu : Đánh giá giá trị của chuỗi xung khuếch tán (DWI) trong chấn đoán ung thư tuyến tiền liẹt (UTTTL) ở vùng ngoại vi (NV) và vùng chuyển tiểp (CT). Phương tiện và phương pháp: Chúng tôi thu thập số liệu của 74 bệnh nhân gồm 296 tổn thương đã được chụp cộng hưởng từ (CHT) tuyến tiền liệt (TTL) 3.0 tesla và đã có kết quả mô bênh học. Tổn thương nghi ngờ UTTTL được phân độ bằng phân độ PIRADs cho chuỗi xung DWI theo PIRADs 2.1 từ đó phân tích mối tương quan giữa hình đặc điểm hình ảnh trên

${ }^{1}$ Trường Đại họ Y Hà Nội

${ }^{2}$ Bênh viên Hữu Nghi Việt Đức

Chịu trách nhiệm chính: Nguyễn Thị Hải Anh

Email: haianhnguyen.918@gmail.com

Ngày nhận bài: 2.6.2021

Ngày phản biên khoa hoc: 29.7.2021

Ngày duyệt bài: 9.8.2021

\section{Nguyễn Thị Hải Anh ${ }^{1}$, Nguyễn Duy Hùng ${ }^{1,2}$}

DWI và mô bênh hoc của tổn thương. Kết quả: Trong số 74 bênh nhân với 296 tổn thương, $182(61,5 \%)$ tổn thương nghi ngờ trên DWI (42,8\% ở NV; $57,2 \%$ ở CT). Phân tích hồi quy chỉ ra có mối liên quan đáng chú ý giữa độ DWI cao và mức độ nă̆ng trên mô bệnh học thể hiện bằng điểm Gleason (tất cả có $p<0,05$ ). Tỉ lệ tương quan giữa độ DWI và kết quả mô bệnh học là $77,0 \%$, NV cao hởn CT $(87,8 \%$ và $69,9 \%$ với $p=$ $0,006)$. Kết quả này chứng minh có mối tương quan tuyến tính giữa sự tăng lên độ DWI và mức độ ác tính của tổn thương. Kết luận: Trong xác định ung thư, DWI chính xác hơn ở vùng ngoại vi so với vùng chuyển tiếp. Phân độ DWI càng cao thì độ chính xác càng cao. Trong khi đó, UTTTL có thể tìm thây ở một phần nhỏ case có DWI âm tính.

Tư khóa: ung thư tuyến tiền liêt, xung khuếch tán DWI, PIRADs, cộng hưởng từ tuyến tiền liệt.

\section{SUMMARY}

VALUE OF DIFFUSION-WEIGHTED 